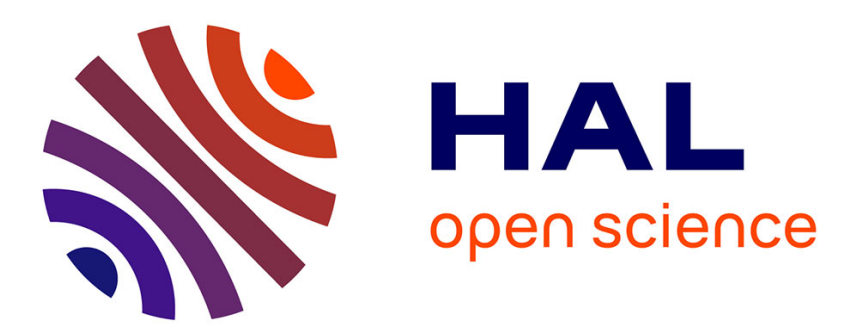

\title{
A dialectical based model coherent with inventive and optimization problems
}

Sébastien Dubois, Thomas Eltzer, Roland de Guio

\section{To cite this version:}

Sébastien Dubois, Thomas Eltzer, Roland de Guio. A dialectical based model coherent with inventive and optimization problems. Computers in Industry, 2009, 60 (8), pp.575-583. 10.1016/j.compind.2009.05.020 . hal-00794341

\section{HAL Id: hal-00794341 \\ https://hal.science/hal-00794341}

Submitted on 25 Feb 2013

HAL is a multi-disciplinary open access archive for the deposit and dissemination of scientific research documents, whether they are published or not. The documents may come from teaching and research institutions in France or abroad, or from public or private research centers.
L'archive ouverte pluridisciplinaire HAL, est destinée au dépôt et à la diffusion de documents scientifiques de niveau recherche, publiés ou non, émanant des établissements d'enseignement et de recherche français ou étrangers, des laboratoires publics ou privés. 


\title{
A dialectical based model coherent with inventive and optimization problems
}

\author{
Sébastien Dubois ${ }^{1}$, Thomas Eltzer ${ }^{2}$, Roland De Guio ${ }^{1}$ \\ ${ }^{1}$ INSA de Strasbourg, 24 bld. de la Victoire, 67000 STRASBOURG \\ ${ }^{2}$ Active Innovation Management, 42 rue de Sources, 92160 ANTONY.
}

\begin{abstract}
In an array of problem solving methods, one can traditionally distinguish two kinds of problems: one is a problem that has solutions in a search space and the other is a problem that doesn't have solutions in a given space. The later problem so called solutionless problem or inventive problem requires an inventive approach to reformulate the problem and dialectical thinking brings benefits in the process. The framework used to formulate problems in a dialectical approache is contradiction. Identification of contradictions plays an important role in distinguishing solutionless problems: a contradiction exists when no solution can be found, and a solution exists when no contradiction can be found. In this article the inadequacy of existing frameworks in satisfying this requirement is demonstrated and a framework that fits this requirement is proposed.
\end{abstract}

Keywords: problem formulation, dialectical thinking, contradiction, optimization, inventive design.

\section{Introduction}

On the table of problem solving methods, one can traditionally distinguish two kinds of problems: those that can be solved by optimization methods and those that cannot be solved by such methods [1]. A problem can be characterized by a certain "research space" that must be investigated by optimisation methods and within which the solution is sought. Different optimisation techniques can be used to do this investigation [2]. For example, each point of this research space can be evaluated according to the problem description. If it solves the problem, then the point is a solution and the search ends, otherwise a further point of the research space is checked. Another optimization technique can, for example, consider the gradient of satisfaction between two different points to choose the most efficient search path. One of the key issues of the optimization technique is the time required to find a solution, if it exists within the research space. If no point of the research space solves the problem, then, no optimization technique will be able to bring a solution. In this article, we make the hypothesis that if a solution exists in the research space, it is possible to find it with at least one optimization method, i.e. it can be solved by optimization methods. Problems that can be solved by optimization methods lead to a product slight improvement and one can name this "routine design" [3]. On the contrary, if no solution exists in the research space, one must imagine a completely new system to fit the problem's requirements. This can be named "inventive design" [4]. In technical system design, points in the research space are relative to technical systems. In this article, it is considered that a problem is a situation in which a given objective cannot be met by the existing possible systems of the research space. Thus problem solving can be seen as a process which aims at transforming this initial situation in which the objective and the possible systems do not match, in a final situation in which at least one system fits the objective [5]. In this article, we consider that a problem is characterized by at least one system, and an objective that no system in the research space can fully satisfy. This objective can be defined by a set of evaluation parameters [6]. An inventive solution is a description of a system, which may not belong to the initial research space, but which fully satisfies the objective.

The research space can be described by a set of parameters and a set of possible values for each of them. Any system can further be described by an assignment of a value to all these parameters. These parameters can be called "action parameters" [6].

To understand which kind of knowledge has to be collected, the way knowledge is considered during problem formulation is important; some problem solving approaches are based on materialist dialectics, which consider that every system is in permanent change due to contradictions. According to these approaches, understanding a system requires the identification of contradictions. This way of 
thinking leads to the synthesis of problem solving methods for design, as, for example, methods from TRIZ. Our objective in this article is to find a way to use dialectical principles to describe and further solve inventive problems. Such a model has to reveal the shortcomings in a problem to guide its transformation from a problem which cannot be treated with classical optimization techniques into a solvable one. Moreover, this contradiction definition has to be applicable for all the situations that have no solution with optimization techniques, and only for these representations.

In this article, an overview of dialectical thinking and its use in problem formulation and resolution is depicted in section 2. Inventive problems resolution methods based on dialectical thinking is then presented. In section 3, we show that existing contradiction models do not satisfy the equivalence requirement and a model satisfying this requirement will be proposed in section 4 . Section 5 draws conclusions and perspectives.

\section{Stating and solving a problem using dialectical thinking}

One of the main characteristics of dialectical thinking is that it places its entire emphasis on change [7]. Dialectics is the process of looking for contradictions inside a phenomenon as the main guide to what is going on and what is likely to happen. Basing system evolution on the elicitation, understanding and resolution of contradictions is also one of the main characteristics of TRIZ [8]. TRIZ is a theory aiming at understanding the way technical systems evolve as well as the development of methods and tools for inventive technical problem solving. The principles of TRIZ have been widely applied in many domains $[9,10,11]$. One of the benefits, which will be considered here, is the existence of models to represent problems as contradictions and of principles to guide the change from a non-solvable problem to a solvable one.

\subsection{Dialectical thinking}

\subsubsection{Main dialectical axioms}

In dialectics, phenomena are mainly characterized by their abilities to change. These changes are initiated by contradictions. Dialectics is looking for contradictions inside a phenomenon as the main guide to understand what is going on and what is likely to happen. Thus Hegel calls the dynamic aspect of phenomenon the negation. Whereas the syllogism is based on the assumption of logical identity, where A is equal to A and A is not non-A; Hegel's contradiction, and more generally dialectical thinking, challenges this notion [12], considering that A is not simply A. Each phenomenon also contains its opposite and, by this, the faculty to evolve from a state to another one.

To understand the phenomenon and to be able to guide the changes, it is required to understand well how the phenomenon operates. Contradictions appear due to a gap between the actual state of the phenomenon and desired behaviour. To be able to guide the changes, i.e. to be able to make the phenomenon evolve from the actual state to the desired one, a good understanding of the phenomenon is required. It means that empirical knowledge connected to the problem is necessary to model the problem and to change it.

Dialectical materialism is a method to investigate reality. Lenin said "dialectics is the teaching which shows how opposites can be and how they happen to be (how they become) identical - under what conditions they are identical, transforming themselves into one another, - why the human mind should take these opposites not as dead, rigid, but as living, conditional, mobile, transforming themselves into one another" [13].

Dialectical methods are based on the elicitation of problems, analysis of the situation, consideration of the model problem to build a model solution and then on the application of the solution to change the initial situation. Problems are represented as contradictions [14]. To identify the contradictions, both the actual state of the studied systems and objectives have to be well defined. This satisfactory definition can be reached through the model of actual state by empirical knowledge in accordance with the objective's point of view. Understanding phenomenon behaviour enables one to make changes going from the quantitative to the qualitative, thus causing its evolution [15].

The mechanisms of evolution enabling a transition from a quantitative evolution to a qualitative one have to be identified to formulate problems in dialectical approaches. This leads to an understanding of the problem core. The formulation of problems through contradictions pattern enables one to focus 
on what seems impossible to change in the situation and so provides a universal understanding of the problems regardless of the problem's domain. Especially when problems tackle multiple contexts, the use of contradictions enables one to deal with the multidimensional aspects of the situation, because the contradiction pattern is not specific to any domain.

In terms of use, the elicitation of contradictions raises two questions: the identification of deep contradictions and the resolution of obtained contradictions [16]. Deep contradictions act as a means to change the situation, whereas other contradictions could be easily resolved but their resolution does not satisfy the objectives. Once a contradiction is elicited, it is necessary to apply the problem modifications that enable its resolution to satisfy the objectives.

\subsection{TRIZ and OTSM-TRIZ}

\subsubsection{Short TRIZ history}

In technical systems design, a complete theory based on dialectical thinking axioms has been constructed: TRIZ (Russian acronym for "Theory of solving inventive problems") [8]. It was conceptualized by G. Altshuller. One of the main ideas is to use contradictions as a way to describe problems. More than 50 years after the first publication on this problem solving approach [17], some additions to it have been proposed, among others: The General Theory of Advanced Thinking (Russian acronym: OTSM), The Theory of Development of a Strong Creative Personality (TRTL) and The Theory of the Evolution of Technological Systems (TRTS). It is in the overlapping area of OTSM-TRIZ that the idea of contradiction is the most clearly defined [11]. Therefore, by using the OTSM-TRIZ idea of contradiction the goal of this article will be tested. In TRIZ, three levels of contradiction are proposed, corresponding to different abstraction levels. This idea of more than one level of contradiction is also present in OTSM-TRIZ.

\subsubsection{Idea of contradiction in OTSM-TRIZ}

Three types of contradictions have been proposed in TRIZ [18]: administrative contradiction, technical contradiction and physical contradiction. These three different levels aim at representing the problem at different stages of understanding the means to act in the situation.

- The administrative contradiction is the expression of an identified objective without any means of reacting to the situation;

- The technical contradiction is the expression of two opposite requirements;

- The physical contradiction is the expression of two contradictory yet required states of a same parameter.

The administrative contradiction has not been kept in OTSM-TRIZ, as this contradiction definition only refers to the objective and no corresponding solving tool exists. The two kinds of contradictions that are proposed in OTSM-TRIZ are the Contradiction of the System (later referred to as "CS") and the Contradiction of the Parameter (later referred to as "CP"), which respectively generalize the TRIZ technical contradiction and physical one. Moreover a System of Contradiction (later named "SC") is proposed in the frame of OTSM-TRIZ to build coherence between the levels of the Contradiction of the System (CS) and the Contradiction of the Parameter (CP), as illustrated on figure 1.

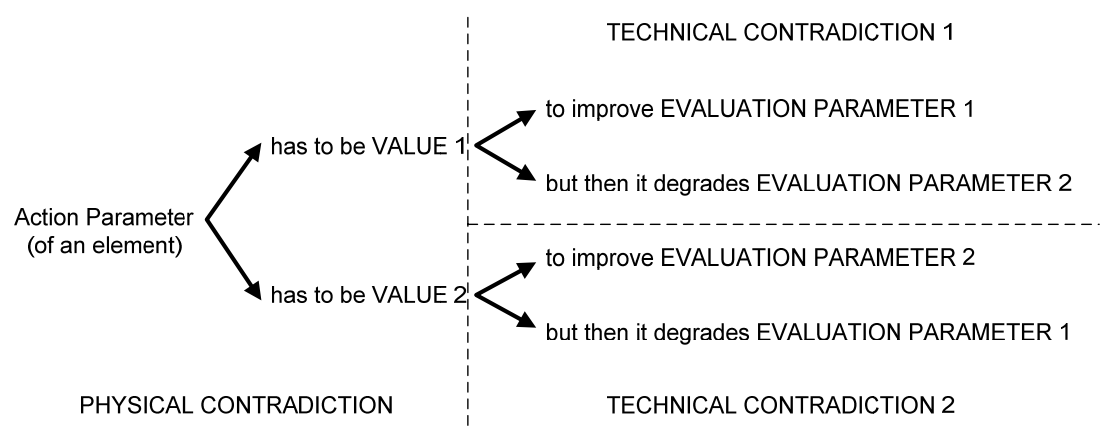

Figure 1. System of Contradiction 
The coherence is achieved by the requirement of the two incompatible Contradictions of the Parameter states.

\section{Stating a System of Contradiction}

In order to study the benefits and limits of OTSM-TRIZ SC, it will be applied on a real case study.

\subsection{Description of the case study}

The case study used in this article is about train architecture design. The objective of this task is to obtain a train architecture design able to adapt its own passenger access area height to the station height, in order to eliminate the vertical gap (Figure 2a shows unmatching passenger access area and station; Figure $2 \mathrm{~b}$ shows matching access zone and station). To match the access area and the station, a vertical movement needs to be achieved (as station height are not constant, the train access area can be too high or too low). A simplified description of this design task considers three action parameters to describe the search space:

- the type of vertical movement: the first option is that the train circulation height is high and the train is lowered when it arrives in the station. The second option is that circulation height is low and train is raised for perfect matching;

- the type of mobile zone: either the whole train is moved vertically, or only the passenger access area is moved

- the motorization configuration: either the motors are located in the center of the bogie or outside the wheels. Figure 3 shows a classic train bogie.

Since two possibilities exist for each of these three parameters, the search space is made of eight points, i.e. eight different train design configurations: for example raising the access area of a train with external motorization, or lowering the whole train which also has external motorization, etc. At this stage of the design process, the possible configurations are evaluated by 10 evaluation parameters, among which:

- The possibility to initiate the vertical movement although the train has not yet stopped in the station;

- Train inner floor flatness;

- Energy needed to make the vertical movement. 

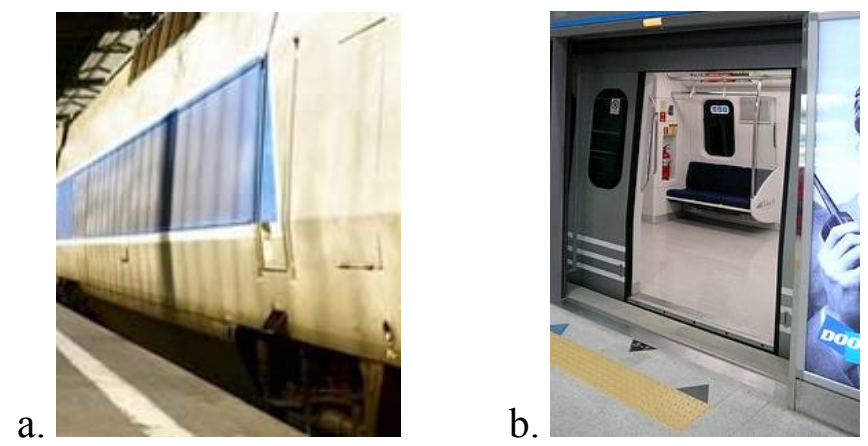

Figure 2. Non matching train and platform height (from http://www.art.com), compared to matching train and platform (from http://farm1.static.flickr.com)

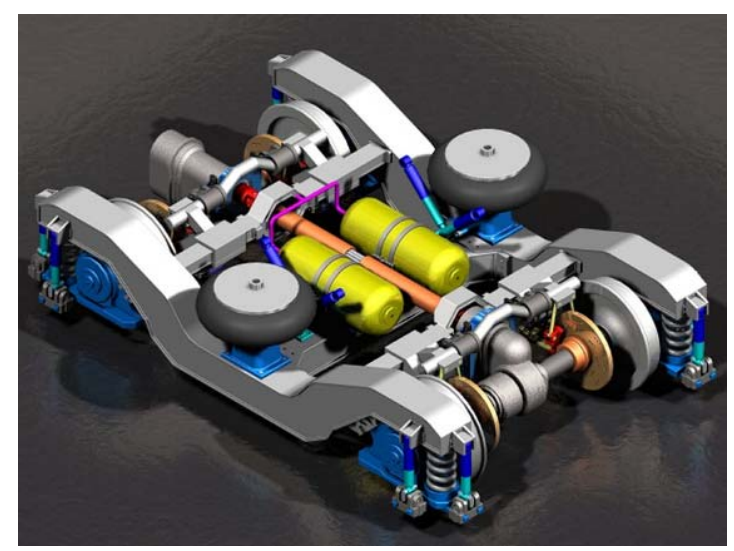

Figure 3. A bogie, from www.solidworks.com

A team of four train architecture experts are interviewed to evaluate the configurations versus the ten parameters. Table 1 shows the possible configurations and their final evaluation.

\subsection{Representing information}

The objective is to investigate applying dialectical models to describe a problem out of a set of information. This technical information can be obtained by: expert opinions (as in the case study), result from experiment designs, theoretical models, computer based simulations, data bases, etc. This set of technical data is represented in the chart below (see table 1).

Table 1 shows the technical information given by experts. Each row is one of the possible train architectures, described as a combination of values for the set of action parameters. Generally speaking, this group of parameters is named $X^{\prime}$ and is composed of $n$ parameters: $X 1, . ., X n(E q 1)$. A specific assignment of $X^{\prime}$ is noted X'. Only two different values can exist for each Action Parameter, so they are noted 0 or 1 . The meaning of 0 and 1 is defined in table 2. For example, when X1 (type of vertical movement) is assigned the value 1 , it means that the movement is upward. If X1 is assigned 0 , it means that the movement is downward.

Eq 1: $X^{\prime}=(X 1, . ., X k, . ., X n)$

A second set of parameters is used to describe the objective the system should meet. They are Evaluation Parameters [6]. This second group is named $Y^{\prime}$ and is composed of $m$ parameters: $\mathrm{Y} 1, . ., \mathrm{Ym}(\mathrm{Eq} 2)$. In the example: $\mathrm{Y}^{\prime}=(\mathrm{Y} 1, \mathrm{Y} 2, \mathrm{Y} 3, \mathrm{Y} 4, \mathrm{Y} 5, \mathrm{Y} 6, \mathrm{Y} 7, \mathrm{Y} 8, \mathrm{Y} 9, \mathrm{Y} 10)$. Again, a particular value of $\mathrm{Yj}_{\mathrm{j}}$ is noted $\mathrm{yj}$, and a value of the whole group $\mathrm{Y}^{\prime}$ is noted $\mathrm{y}^{\prime}$. Each train configuration can be evaluated versus this set of Evaluation Parameters: if the Evaluation Parameter Yj is satisfying, its value yj is 1 (see table 2). If the Evaluation Parameter is not satisfying, its value yj is 0 .

Eq 2: $\mathrm{Y}^{\prime}=(\mathrm{Y} 1, . ., \mathrm{Yj}, . ., \mathrm{Ym})$

Therefore, the first row of Table 1 means that a train architecture design in which the whole train $(x 2=1)$ is raised $(x 1=1)$ and where motors are external to bogie $(x 3=1)$ satisfies only one criteria: it is possible to start vertical movement when the train moves $(\mathrm{y} 2=1)$. 
The content of Table 1 defines a function fj for each evaluation criteria $Y j$ which defines the value of yj based on the assigned value of $X^{\prime}: Y j=f j\left(X^{\prime}\right)$. In the example, $f 1$ is defined, among others, by the following points:

- Train configuration $\# 1$ : if $x^{\prime}=(1,1,1)$ then $\mathrm{fl}\left(\mathrm{x}^{\prime}\right)=0$;

- Train configuration $\# 2$ : if $\mathrm{x}^{\prime}=(0,1,1)$ then $\mathrm{fl}\left(\mathrm{x}^{\prime}\right)=0$;

- Train configuration $\# 3$ : if $\mathrm{x}^{\prime}=(1,1,0)$ then $\mathrm{fl}\left(\mathrm{x}^{\prime}\right)=1$;

etc.

\begin{tabular}{|c|c|c|c|c|c|c|c|c|c|c|c|c|c|}
\hline & $\left|\begin{array}{c}X 1 \text { : type of } \\
\text { vertical } \\
\text { movement }\end{array}\right|$ & $\begin{array}{c}\text { X2: } \\
\text { type of } \\
\text { mobile } \\
\text { zone }\end{array}$ & $\begin{array}{c}\text { X3: } \\
\text { motorisation } \\
\text { configuration }\end{array}$ & $\begin{array}{c}\text { Y1: } \\
\text { Height of } \\
\text { module } \\
\text { stairs }\end{array}$ & \begin{tabular}{|c|} 
Y2: \\
possibility \\
to make \\
movement \\
when train \\
moves \\
\end{tabular} & $\begin{array}{c}\text { Y3: height of } \\
\text { maximum } \\
\text { ramp in } \\
\text { corridor, } \\
\text { when train is } \\
\text { stopped }\end{array}$ & $\begin{array}{c} \\
\text { Y4: } \\
\text { floor } \\
\text { flatness }\end{array}$ & \begin{tabular}{|c|} 
Y5: height of \\
maximum \\
ramp in \\
corridor, \\
when train \\
moved
\end{tabular} & $\begin{array}{c}\text { Y6: } \\
\text { necessity to } \\
\text { come back } \\
\text { in nominal } \\
\text { position to } \\
\text { drive }\end{array}$ & $\begin{array}{c}\text { Y7: } \\
\text { inner } \\
\text { height }\end{array}$ & $\begin{array}{l}\text { Y8: possibility } \\
\text { to propose } \\
\text { dynamicity as } \\
\text { an optioin and } \\
\text { not as a base }\end{array}$ & $\begin{array}{c}\text { Y9: } \\
\text { difficulty to } \\
\text { make } \\
\text { movement }\end{array}$ & $\begin{array}{c}\text { Y10: } \\
\text { energy } \\
\text { needed to } \\
\text { make } \\
\text { movement }\end{array}$ \\
\hline$x^{\prime} 1$ & 1 & 1 & 1 & 0 & 1 & 0 & $\overline{0}$ & 0 & 0 & $\overline{0}$ & 0 & 0 & 0 \\
\hline$x^{\prime} 2$ & 0 & 1 & 1 & 0 & 0 & 1 & 1 & 1 & 0 & 0 & 0 & 0 & 0 \\
\hline$x^{\prime} 3$ & 1 & 1 & 0 & 1 & 1 & 0 & 0 & 0 & 0 & 0 & 0 & 0 & 0 \\
\hline \begin{tabular}{|l|}
$x^{\prime} 4$ \\
\end{tabular} & 0 & 1 & 0 & 1 & 0 & 0 & 0 & 0 & 0 & 0 & 0 & 0 & 0 \\
\hline \begin{tabular}{|l|}
$x^{\prime} 5$ \\
\end{tabular} & 1 & 0 & 1 & 0 & 0 & 0 & 0 & 0 & 1 & 1 & 1 & 1 & 1 \\
\hline$x^{\prime} 6$ & 0 & 0 & 1 & 0 & 0 & 0 & 0 & 1 & 1 & 1 & 1 & 1 & 1 \\
\hline \begin{tabular}{|l|}
$x^{\prime} 7$ \\
\end{tabular} & 1 & 0 & 0 & 0 & 0 & 0 & 0 & 0 & 1 & 1 & 1 & 1 & 1 \\
\hline \begin{tabular}{|l|}
$x^{\prime} 8$ \\
\end{tabular} & 0 & 0 & 0 & 0 & 0 & 0 & 0 & 1 & 1 & 1 & 1 & 1 & 1 \\
\hline
\end{tabular}

Table 1. Possible configurations and their evaluation

\begin{tabular}{|l|c|c|c|}
\hline \multicolumn{1}{|c|}{$\begin{array}{c}\text { ×1: Type of } \\
\text { vertical } \\
\text { movement }\end{array}$} & $\begin{array}{c}\times 2 \text { : Type of } \\
\text { mobile zone }\end{array}$ & $\begin{array}{c}\text { ×3: } \\
\text { Motorisation } \\
\text { configuration }\end{array}$ \\
\cline { 2 - 4 } & Raise & Whole train & $\begin{array}{c}4,6 \text { or } 8 \\
\text { external } \\
\text { engines }\end{array}$ \\
\hline "1" means: & Lower & Access area & $\begin{array}{c}8 \text { central } \\
\text { engines }\end{array}$ \\
\hline
\end{tabular}

Table 2. Meaning of the values for the action parameters

The information contained in such a table could also be used to assist selection (decide which architecture is the best out of the set), to optimize choice (find the configuration that satisfies each criteria as rapidly as possible), etc. Analyzing Table 1 shows that no solution exists in the search space. None of the eight configurations based on the search space, is able to satisfy the full list of evaluation parameters. Therefore, no acceptable architecture can be found using an optimization technique. This problem cannot be solved by optimization methods. The use of OTSM-TRIZ contradictions to describe this problem will now be investigated.

\subsection{Searching for a System of Contradictions (SC)}

In this chapter, a System of Contradiction is analysed in a set of information like Table 1.

\subsubsection{Administrative contradiction (AC)}

The goal of the administrative contradiction in the Classical TRIZ frame is to point out that the stated objective cannot be reached. Whatever the configuration, it never completely fits the requirement. This means that, having described the objective with a set of evaluation parameters, there is always at least one evaluation parameter which is not satisfied. Therefore the property on which the administrative contradiction is based is that: for any possible configuration (in the investigated search space) at least one evaluation parameter is not satisfied, which means that the situation has no solution. This property can be seen in a chart like Table 1 however, among the complete list of possibilities, there exists no line where each evaluation parameter is noted 1 .

\subsubsection{Contradiction of the System (CS)}

A Contradiction of the System, as proposed by OTSM-TRIZ, relates to a couple of evaluation parameters: $\mathrm{Y} 1$ and $\mathrm{Y} 2$. A CS is based on the following property of $(\mathrm{Y} 1, \mathrm{Y} 2)$ : if $\mathrm{Y} 1$ is satisfying, then Y2 is not satisfying [11]. Let us name this first Contradiction of System CS\#1. The contradiction named CS\#2 is based on the symmetrical property: if Y2 is satisfying, then Y1 is not satisfying. Graphically, CS\#1 can be identified in a chart by two columns in which the only possible pairs of values are: $(\mathrm{y} 1, \mathrm{y} 2)=(1,0),(\mathrm{y} 1, \mathrm{y} 2)=(0,1)$ or $(\mathrm{y} 1, \mathrm{y} 2)=(0,0)$. It should be noted that, as an evaluation 
parameter has only two states (either satisfying or not), CS\#1 and CS\#2 base properties are equivalent. Therefore, the existence of CS\#1 is equivalent to the existence of CS\#2 and also equivalent to the property that $\mathrm{Y} 1$ and $\mathrm{Y} 2$ are never simultaneously satisfying: no couple $(1,1)$ can be found in their two columns. Table 3 shows an example where, for the two columns representing Y1 and Y2, CS\#1 and CS\#2 can be found. It should also be noted that if there is at least one CS, there is an Administrative Contradiction. This means that the property on which the CS is based is more restrictive than the one on which AC is based.

\begin{tabular}{|c|c|c|c|}
\hline & $\mathrm{Y} 1$ & $\mathrm{Y} 2$ & $\mathrm{~V} 3$ \\
\hline$x^{\prime} 1$ & & 0 & 0 \\
\hline$x^{\prime} 2$ & 1 & 0 & 1 \\
\hline$x^{\prime} 3$ & 0 & 1 & 0 \\
\hline$x^{\prime} 4$ & 0 & 0 & 1 \\
\hline$x^{\prime} 5$ & 0 & 1 & 0 \\
\hline$x^{\prime} 6$ & 0 & 0 & 0 \\
\hline$x^{\prime} 7$ & 0 & 0 & 1 \\
\hline$x^{\prime} 8$ & 0 & 1 & 1 \\
\hline
\end{tabular}

Table 3. Example of contradiction of system

In [6] an example with no solutions in the search space and where no CS can be found is presented, because each evaluation parameter of any possible pair can be simultaneously satisfied. This shows that the absence of solution is not equivalent to the existence of a CS.

\subsubsection{Contradiction of the Parameter (CP)}

The definition of the $\mathrm{CP}$ is linked to an action parameter, named $\mathrm{X} 1$, which influences both $\mathrm{Y} 1$ and Y2. A CP is defined by the two following properties [11]:

- when $\mathrm{X} 1$ is assigned a value $\mathrm{V} 1$, then $\mathrm{Y} 1$ is satisfying but $\mathrm{Y} 2$ is not satisfying;

- when X1 is assigned a value V2 (different than V1), then Y2 is satisfying but Y1 is not satisfying.

This means that the values of the triplet $(\mathrm{X} 1, \mathrm{Y} 1, \mathrm{Y} 2)$ can only be either $(\mathrm{V} 1,1,0)$ or $(\mathrm{V} 2,0,1)$, whatever the assignments for the other action parameters $(\mathrm{X} 2, . ., \mathrm{Xn})$. Furthermore, as defined and illustrated in chart 2 an action parameter can only be assigned either 0 or 1 . Therefore, graphically, a CP is based on the following property of the values for three columns representing X1, Y1 and Y2:

- either their values are $(0,0,1)$ or $(1,1,0)$. This is shown in table $4 \mathrm{a}$

- or their values are $(1,0,1)$ or $(0,1,0)$. This is illustrated in table $4 \mathrm{~b}$.

It should be noted that one of the consequences of such a property is that the couple $(\mathrm{Y} 1, \mathrm{Y} 2)$ is never assigned neither $(0,0)$ nor $(1,1)$. If a CP exists, then the two evaluation parameters can never be simultaneously unsatisfying. Therefore, the property on which the $\mathrm{CP}$ is based is more restrictive than the one which the CS is based on. Consequently, the example proposed in [6] is a situation with neither solution nor CP: there is no equivalence between the absence of a solution and the existence of a CP.

\begin{tabular}{|r|rr|rr|r|}
\hline \multicolumn{1}{|c|}{$\times 1$} & $\times 2$ & $\times 3$ & $\gamma_{1}$ & $\gamma_{2}$ & $\gamma_{3}$ \\
\hline 0 & 0 & 0 & 0 & 1 & 1 \\
0 & 0 & 1 & 0 & 1 & 0 \\
0 & 1 & 0 & 0 & 1 & 0 \\
0 & 1 & 1 & 0 & 1 & 1 \\
1 & 0 & 0 & 1 & 0 & 1 \\
1 & 0 & 1 & 1 & 0 & 0 \\
1 & 1 & 0 & 1 & 0 & 1 \\
1 & 1 & 1 & 1 & 0 & 1 \\
\hline
\end{tabular}

\begin{tabular}{r|rr|rr|r|}
\hline \multicolumn{1}{|r|r}{$\times_{1}$} & $\times_{2}$ & $\aleph_{3}$ & $\gamma_{1}$ & $\gamma_{2}$ & $\gamma_{3}$ \\
\hline 0 & 0 & 0 & 1 & 0 & 1 \\
0 & 0 & 1 & 1 & 0 & 0 \\
0 & 1 & 0 & 1 & 0 & 0 \\
0 & 1 & 1 & 1 & 0 & 1 \\
1 & 0 & 0 & 0 & 1 & 1 \\
1 & 0 & 1 & 0 & 1 & 0 \\
1 & 1 & 0 & 0 & 1 & 1 \\
1 & 1 & 1 & 0 & 1 & 1 \\
\hline
\end{tabular}


Table 4. Example of contradiction of parameter

As a result of the definition of Administrative, System and Parameter contradictions, it appears that the properties which they are based on have the following logical relation: if a CP exists, then a CS exists and then an $\mathrm{AC}$ exists.

\subsubsection{Applicability to the case example}

The chart describing the case example clearly shows that none of the possible configurations completely fits the objective described by the 10 parameters $\mathrm{Y} 1, . ., \mathrm{Y} 10$. In each row, there is at least one " 0 " in the portion relevant to the 10 evaluation parameters. For example, a train architecture design (configuration $\left.\mathrm{x}^{\prime} 1\right)$ in which the whole train $(\mathrm{x} 2=1)$ is raised $(\mathrm{x} 1=1)$ and where motors are external to the bogie $(\mathrm{x} 3=1)$ does not satisfy floor flatness $(\mathrm{y} 4=0)$.

Table 5 shows the analysis of each of the 45 possible pairs of evaluation parameters. If both of the evaluation parameters are simultaneously satisfied in at least one out of the possible configurations (from x' 1 to $x^{\prime} 8$ ), then this configuration is mentioned in the corresponding cell. For example, if the train architecture is designed in such a way that the whole train is raised, and there are 8 central motors (configuration X'3) then both the height of module stairs (Y1) and the possibility of making the movement when train moves (Y2) are satisfying. The cell corresponding to Y1 and Y2 intersection in Table 5 is labeled " $x$ ' 3 ". The grey cells either have no sense (diagonal) or do not need to be analyzed, as this matrix is obviously symmetric. Therefore, each empty white cell of the chart corresponds to a CS between the two evaluation parameters. This chart shows that $26 \mathrm{CS}$ can be found in the case example. For example, there is a CS between Y1 and Y3: if the height of module stairs (Y1) is satisfying, then the height of maximum ramp in the corridor when train is stopped (Y3) is not satisfying, and vice versa. It is impossible to simultaneously satisfy these two parameters.

\begin{tabular}{|c|c|c|c|c|c|c|c|c|c|c|}
\hline & \begin{tabular}{|l} 
Y1: \\
Height of \\
module \\
stairs
\end{tabular} & $\begin{array}{c}\text { Y2: } \\
\text { possibility } \\
\text { to make } \\
\text { movement } \\
\text { when train } \\
\text { moves }\end{array}$ & $\begin{array}{l}\text { Y3: height of } \\
\text { maximum } \\
\text { ramp in } \\
\text { corridor, } \\
\text { when train is } \\
\text { stopped }\end{array}$ & $\begin{array}{c}\text { Y4: } \\
\text { floor } \\
\text { flatness }\end{array}$ & \begin{tabular}{|c|} 
Y5: height of \\
maximum \\
ramp in \\
corridor, \\
when train \\
moved \\
\end{tabular} & \begin{tabular}{|c|} 
Y6: \\
necessity to \\
come back \\
in nominal \\
position to \\
drive \\
\end{tabular} & $\begin{array}{l}\text { Y7: inner } \\
\text { height }\end{array}$ & $\begin{array}{c}\text { Y8: possibility } \\
\text { to propose } \\
\text { dynamicity as } \\
\text { an optioin and } \\
\text { not as a base } \\
\end{array}$ & $\begin{array}{c}\text { Y9: difficulty to } \\
\text { make } \\
\text { movement }\end{array}$ & $\begin{array}{c}\text { Y10: energy } \\
\text { needed to } \\
\text { make } \\
\text { movement }\end{array}$ \\
\hline Y1: Height of module stairs & & $x^{\prime} 3$ & & & & & & & & \\
\hline $\begin{array}{l}\text { Y2: possibility to make } \\
\text { movement when train moves }\end{array}$ & & & & & & & & & & \\
\hline $\begin{array}{l}\text { Y3: height of maximum ramp } \\
\text { in corridor, when train is } \\
\text { stopped }\end{array}$ & & & & $x^{\prime} 2$ & $x^{\prime} 2$ & & & & & \\
\hline Y4: floor flatness & & & & & $\begin{array}{l}x< \\
x^{\prime} 2 \\
\end{array}$ & & & & & \\
\hline $\begin{array}{l}\text { Y5: height of maximum ramp } \\
\text { in corridor, when train moved }\end{array}$ & & & & & & $x^{\prime} 6, x^{\prime} 8$ & $x^{\prime} 6, x^{\prime} 8$ & $x^{\prime} 6, x^{\prime} 8$ & $x^{\prime} 6, x^{\prime} 8$ & $x^{\prime} 6, x^{\prime} 8$ \\
\hline $\begin{array}{l}\text { Y6: necessity to come back } \\
\text { in nominal position to drive }\end{array}$ & & & & & & & $x^{\prime} 5, x^{\prime} 6, x^{\prime} 7, x^{\prime} 8$ & $x^{\prime} 5, x^{\prime} 6, x^{\prime} 7, x^{\prime} 8$ & $x^{\prime} 5, x^{\prime} 6, x^{\prime} 7, x^{\prime} 8$ & $x^{\prime} 5, x^{\prime} 6, x^{\prime} 7, x^{\prime} 8$ \\
\hline Y7: inner height & & & & & & & & $x^{\prime} 5, x^{\prime} 6, x^{\prime} 7, x^{\prime} 8$ & $x^{\prime} 5, x^{\prime} 6, x^{\prime} 7, x^{\prime} 8$ & $x^{\prime} 5, x^{\prime} 6, x^{\prime} 7, x^{\prime} 8$ \\
\hline $\begin{array}{c}\text { Y8: possibility to propose } \\
\text { dynamicity as an optioin and } \\
\text { not as a base }\end{array}$ & & & & & & & & & $x^{\prime} 5, x^{\prime} 6, x^{\prime} 7, x^{\prime} 8$ & $x^{\prime} 5, x^{\prime} 6, x^{\prime} 7, x^{\prime} 8$ \\
\hline $\begin{array}{c}\text { Y9: difficulty to make } \\
\text { movement }\end{array}$ & & & & & & & & & & $x^{\prime} 5, x^{\prime} 6, x^{\prime} 7, x^{\prime} 8$ \\
\hline $\begin{array}{c}\text { Y10: energy needed to make } \\
\text { movement }\end{array}$ & & & & & & & & & & \\
\hline
\end{tabular}

Table 5. Possible combinations of evaluation parameters

However, for each of the 45 possible evaluation pairs, the two parameters can be simultaneously unsatisfying. For example, floor flatness (Y4) and inner height (Y7) are both unsatisfying in a train architecture design where only the access area is raised and in which there are 8 central motors (configuration x'3). Hence, although there are $26 \mathrm{CS}$, there is no CP.

It can be concluded that the case study has one AC, $26 \mathrm{CS}$, but no CP. In [6] was presented an example which had one AC, but no CS. This case study is another counter-example that shows that the presence of an OTSM-TRIZ System of Contradiction is not equivalent to the absence of solution.

\subsection{Logical relations}

\subsubsection{Equivalence requirement}

The purpose of this article is to find a model, based on dialectics, which could be used to describe any situation which cannot be solved by optimization techniques. Therefore, the property, on which this 
dialectical problem model would be based, should be present in any unsolvable problem: if there is no solution in the search space, then this property can be found. Moreover the existence of contradiction is considered equivalent to the presence in the problem model of the property on which the contradiction is built.

The complementary logical implication should also be true: if the property, on which our problem model is based, does not exist in the problem description, then there is a solution in the search space. This means that the property should be absent of any situation that could be solved by optimization methods. This complementary logical implication is needed at least for the two following reasons:

- it would guarantee that any way to eliminate the contradiction would be a solution. If one finds a way to eliminate the contradiction, then one has found a solution ;

- it would help to select the best approach: either optimization techniques (if the property does not exist), or inventive techniques (if the property exists).

\subsubsection{Presence of OTSM-TRIZ SC, absence of solution}

The case example is one of the situations that cannot be solved by optimization. The space in which an optimization method would search for the solution consists of eight points (the eight train architecture design). This space is completely known, as listed in table 1 . The table shows that none of the 8 points of the search space to be investigated is a solution. Therefore, no optimization technique could find a solution. Based on the existing definitions, the use of OTSM-TRIZ contradiction models was tested to describe the absence of solution: in the case example, no System of Contradiction can be found, due to the fact that no Contradiction of Parameter can be found. Thus, the condition to satisfy OTSM System of Contradiction is not equivalent to the absence of solution. The conclusion of this is that there is still a need for a dialectic problem model, based on a property which is equivalent to the absence of solution.

\section{Generalized contradiction (GC)}

In this chapter, we present the Generalized Contradiction model. It is applied on the case example and the equivalence between the absence of solution and the presence of $\mathrm{GC}$ is demonstrated.

\subsection{Definition}

Applying the dialectical approach on a solutionless problem is equivalent to presenting it as an opposition. The very first detected opposition is between the required values of the set of evaluation parameters and the possible values of the set of action parameters. "The problem is unsolvable" means that there is no way to simultaneously create a satisfying value for each evaluation parameter. Each time the action parameters are tuned to provide a satisfying value for a certain portion of Y' (noted Y"1), at least another portion is not satisfying (noted Y"2). This means that the set of action parameter values satisfying $Y$ "1 and the set of values satisfying $Y$ "2 have no intersection.

One can define, for any $\mathrm{Y}^{\prime} \subset \mathrm{Y}^{\prime}, \mathrm{S}\left(\mathrm{Y}^{\prime}\right.$ ') the set of values of $\mathrm{X}$ ' which satisfy each parameter of $\mathrm{Y}$ ":

Eq 3: $\mathrm{S}\left(\mathrm{Y}^{\prime \prime}\right)=\left\{\mathrm{x}^{\prime} \mid \forall \mathrm{Yj} \in \mathrm{Y} ": \mathrm{fj}\left(\mathrm{x}^{\prime}\right)=1\right\}$

Eq 4: $\mathrm{S}(\mathrm{Y} " 1) \cap \mathrm{S}\left(\mathrm{Y}{ }^{\prime \prime 2}\right)=\mathrm{S}\left(\mathrm{Y}^{\prime \prime} 1 \cup \mathrm{Y}{ }^{\prime \prime}\right)$

It should be noted that if there is one, two or three action parameters, $\mathrm{S}\left(\mathrm{Y}^{\prime \prime}\right)$ geometric interpretation is respectively a line, a surface, or a volume. One can now consider a couple (Y'1, Y'2) having the three following properties:

- Y"1 and Y"2 are subsets of $Y^{\prime}: Y^{\prime \prime} 1 \subset Y^{\prime}$ and $Y^{\prime \prime} 2 \subset Y^{\prime}$

- Y"1 and Y"2 have no common parameter : $Y " 1 \cap Y " 2=\phi$

- It is possible to provide satisfying values of each of them: $\mathrm{S}(\mathrm{Y}$ ” 1$) \neq \phi$ and $\mathrm{S}(\mathrm{Y}$ ”2) $\neq \phi$

The base property of the Generalized Contradiction is defined as the property of such a (Y' $1, Y^{\prime}$ ' 2 ) couple detailed in Eq 5: there is no way to simultaneously provide a satisfying value for each parameter of both Y"1 and for each parameter of Y'2. This means that the set of X' values satisfying each parameter of Y"1 has no common value with the set of $X$ ' values satisfying each parameter of Y"2. 
Eq 5: $\mathrm{S}\left(\mathrm{Y}^{\prime \prime} 1\right) \cap \mathrm{S}(\mathrm{Y} " 2)=\phi$.

It should be noted that this means that $S(Y$ "1 $\cup Y$ "2) is empty (see Eq 4).

Table 6 is used to show how a Generalized Contradiction can be found in the chart under consideration. In this set of information, eight possible configurations are listed $X^{\prime}=x^{\prime} 1$ to $X^{\prime}=x^{\prime} 8$ and each is evaluated versus six evaluation parameters (Y1 to Y6). The chart only displays values of $\mathrm{Y}^{\prime}$. Six zones are represented:

- Zone 1 shows that X'1, x'2 and X'3 are the only configurations able to guarantee a satisfying value for $\mathrm{Y}^{\prime \prime} 1=(\mathrm{Y} 1, \mathrm{Y} 2, \mathrm{Y} 3)$. Therefore $\left(\mathrm{x}^{\prime} 1, \mathrm{x}^{\prime} 2, \mathrm{x}^{\prime} 3\right) \subset \mathrm{S}\left(\mathrm{Y}^{\prime \prime} 1\right)$. The fact that in zone 3 and 5 there is at least one 0 in each line proves that $S\left(Y^{\prime \prime} 1\right)=\left(x^{\prime} 1, x^{\prime} 2, x^{\prime} 3\right)$;

- Zone 4 shows that X'4, X'5 and X'6 are the only configurations able to guarantee a satisfying value for $\mathrm{Y}^{\prime \prime} 2=(\mathrm{Y} 4, \mathrm{Y} 5)$. Hence $\left(\mathrm{x}^{\prime} 4, \mathrm{x}^{\prime} 5, \mathrm{x}^{\prime} 6\right) \subset \mathrm{S}\left(\mathrm{Y}^{\prime} 2\right)$. The fact that in zone 2 and 6 there is at least one 0 in each line proves that $S\left(Y^{\prime \prime} 2\right)=\left(x^{\prime} 4, x^{\prime} 5, x^{\prime} 6\right)$. Here again, zone 4 is only filled with " 1 ".

The table in which this graphic property should be researched can of course be obtained after reordering configurations and evaluation parameters.

\begin{tabular}{|c|c|c|c|c|c|c|}
\hline & $\mathrm{Y}_{1}$ & $\mathrm{~V}_{2}$ & 13 & $Y_{4}$ & Y5 & $V_{6}$ \\
\hline$x^{\prime} 1$ & 1 & 1 & 1 & & 0 & 0 \\
\hline$x^{\prime} 2$ & 1 & 1 & 1 & & 1 & 1 \\
\hline$x^{\prime} 3$ & 1 & 1 & 1 & 0 & 1 & 0 \\
\hline$x^{\prime} 4$ & 1 & 0 & 1 & & 1 & 1 \\
\hline$x^{\prime} 5$ & 1 & 21 & 0 & 1 & 1 & 0 \\
\hline$x^{\prime} 6$ & 1 & 0 & 0 & 1 & 1 & 0 \\
\hline$x^{\prime} 7$ & 0 & $\theta$ & 1 & & 0 & 1 \\
\hline$x^{\prime} 8$ & 0 & 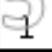 & 1 & & 0 & 1 \\
\hline
\end{tabular}

Table 6. Example of generalized contradiction

\subsection{Equivalence}

In this paragraph the equivalence between the existence of a Generalized Contradiction and the absence of a solution is demonstrated.

\subsubsection{If there is a solution, then there is no GC}

The existence of a solution means that there exists a certain assignment $\mathrm{X}^{\prime *}$ of $\mathrm{X}^{\prime}$ able to satisfy any parameter of $\mathrm{Y}^{\prime}$. Therefore, $\mathrm{x}^{\prime *}$ also creates a satisfying value for any parameter of an evaluation parameter subset. Therefore, for any possible pair $\mathrm{Y}^{\prime} 1 \subset \mathrm{Y}^{\prime}$ and $\mathrm{Y}^{\prime} 2 \subset \mathrm{Y}$ ', $\mathrm{x}$ * belongs to both $\mathrm{S}(\mathrm{Y}$ "1) and $\mathrm{S}(\mathrm{Y}$ "2). This means that the intersection is not empty, i.e. there is no Generalized Contradiction between the pair. This shows that if there is a solution, then there is no GC.

\subsubsection{If there is no $\mathrm{GC}$, then there is a solution}

It will be demonstrated that if there is no solution, then at least one GC can be found. One should start with this hypothesis: there is no solution in the search space. Considering any possible subset $Y$ " $\subset Y$ ' when $Y$ " has only one element denoted by $C \operatorname{ard}(Y ")=1 . Z 1$ is defined as the group of such a $Y$ " (Eq 6). Making the hypothesis that any evaluation parameter can be satisfied at least once (this would mean here that $\mathrm{S}(\mathrm{Y} " \subset \mathrm{Y} / \mathrm{Card}(\mathrm{Y} ")=1)$ is not empty, Eq 7). Facing a situation in which $\mathrm{Yj}$ is never satisfying, the chart can be completed by simply adding a configuration which satisfies $\mathrm{Yj}$. This configuration can be artificial, and just for the sake of stating the problem. This may necessitate the addition of both new action parameters to describe the new set of configuration and new evaluation parameters.

Eq 6: $\mathrm{Z1}=\left\{\mathrm{Y}^{\prime \prime} \subset \mathrm{Y} ' \mid \operatorname{Card}\left(\mathrm{Y}^{\prime \prime}\right)=1\right\}$ 


\section{Eq 7: $\forall Y^{\prime \prime} \in Z 1: S\left(Y^{\prime \prime}\right) \neq \phi$}

One may now consider any possible subset $\mathrm{Y}^{\prime \prime} \subset \mathrm{Y}^{\prime}$ for which $\operatorname{Card}\left(\mathrm{Y}{ }^{\prime}\right)=2$. They are grouped in $\mathrm{Z}$,

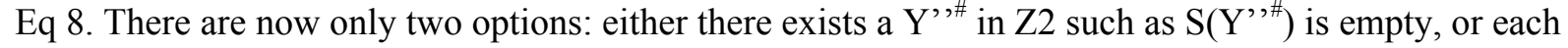
$\mathrm{Y}^{\prime}$ ' of $\mathrm{Z} 2$ like $\mathrm{S}\left(\mathrm{Y}^{\prime}\right.$ ') is not empty. Considering the first option and defining $\mathrm{Y} 1$ and $\mathrm{Y} 2$ the two parameters of $Y^{\prime}$ " a Generalized Contradiction can be formulated between $Y 1$ and Y2, like $\mathrm{S}(\mathrm{Y} 1) \cap \mathrm{S}(\mathrm{Y} 2)=\mathrm{S}(\mathrm{Y} 1 \cup \mathrm{Y} 2)=\mathrm{S}\left(\mathrm{Y}^{,}, \#\right)$ is empty and neither $\mathrm{S}(\mathrm{Y} 1)$ nor $\mathrm{S}(\mathrm{Y} 2)$ are empty.

Eq 8: $\mathrm{Z2}=\left\{\mathrm{Y}^{\prime} \subset \mathrm{Y}^{\prime} \mid \operatorname{Card}\left(\mathrm{Y}^{\prime \prime}\right)=2\right\}$

Eq 9: $\forall \mathrm{Y}^{\prime \prime} \in \mathrm{Z2}: \mathrm{S}\left(\mathrm{Y}^{\prime \prime}\right) \neq \phi$

In the second option $\mathrm{S}\left(\mathrm{Y}^{\prime \prime} \subset \mathrm{Y}\right.$ ') is not empty for any $\mathrm{Y}$ " having two or less parameters (Eq 7 and 9). Then, consider any possible subset $Y^{\prime}$ ' of $Y^{\prime}$ for which $\operatorname{Card}\left(Y^{\prime}\right.$ ') $=3$ and group them in Z3 (Eq 10). One can elaborate the same logical reasoning as in the preceding paragraph: either there exists a Y'"\# in $\mathrm{Z} 3$ so that $\mathrm{S}\left(\mathrm{Y}^{\prime \prime} \#\right)$ is empty or each $\mathrm{Y}$ " of $\mathrm{Z3}$ so that $\mathrm{S}\left(\mathrm{Y}^{\prime \prime}\right)$ is not empty (Eq 11). Consider the first option and let one define $Y$ "\#1 and $Y$ " $\# 2$ two subsets of $Y$ "\#. $Y$ "\#1 and $Y$ " \#2 have either 1 or 2 elements, therefore neither $\mathrm{S}\left(\mathrm{Y}^{\prime}\right.$ '\#1) nor $\mathrm{S}\left(\mathrm{Y}^{\prime}\right.$ '\#2) is empty (properties of $\mathrm{Eq} 7$ and 9 are true). As a consequence, it is possible to identify a Generalized Contradiction between $Y$ ' $\# 1$ and $Y$ " $\# 2$ as $\mathrm{S}(\mathrm{Y}, \# 1) \cap \mathrm{S}(\mathrm{Y}, " \# 2)=\mathrm{S}(\mathrm{Y}, \#)$ is empty.

Eq 10: $\mathrm{Z3}=\left\{\mathrm{Y}^{\prime} \subset \mathrm{Y}^{\prime} \mid \operatorname{Card}\left(\mathrm{Y}^{\prime}\right)=3\right\}$

Eq 11: $\forall Y^{\prime \prime} \in Z 3: S(Y ") \neq \phi$

Now, consider the second option; $\mathrm{S}\left(\mathrm{Y}^{\prime} \subset \mathrm{Y}^{\prime}\right)$ is not empty for any $\mathrm{Y}$ " with three or less parameters (properties described by Eq b, $\mathrm{d}$ and e are true). Then, define $\mathrm{Z} 4$ as the group of possible subset $\mathrm{Y}$ ' ' of $\mathrm{Y}^{\prime}$ for which $\operatorname{Card}\left(\mathrm{Y}^{\prime} \subset \mathrm{Y}^{\prime}\right)=4(\mathrm{Eq} 12)$. Once again, either there exists a $\mathrm{Y}^{\prime} \#$ in $\mathrm{Z} 4$ so that $\mathrm{S}\left(\mathrm{Y}^{\prime} \#\right)$ is empty (and then we can formulate a Generalized Contradiction), or for each Y" of Z4, S(Y") is not empty (and combinations of five parameters should be considered).

Eq 12: $\mathrm{Z4}=\left\{\mathrm{Y}^{\prime} \subset \mathrm{Y}^{\prime} \mid \operatorname{Card}\left(\mathrm{Y}^{\prime}\right)=4\right\}$

This logic can be continued until a Generalized Contradiction is found. It eventually leads to $Y$ " $\subset Y$ ' for which $\operatorname{Card}\left(\mathrm{Y}^{\prime}\right)=\operatorname{Card}\left(\mathrm{Y}^{\prime}\right)$ ie $\mathrm{Y}^{\prime}$ ' is the whole set of evaluation parameters. As there is no solution in the search space, $\mathrm{S}\left(\mathrm{Y}^{\prime}\right)$ is obviously empty. Consequently, it is possible to build a Generalized Contradiction between any pair Y" 1 and $Y$ " 2 such as $Y$ " $1 U Y$ " $2=Y$ '. This shows that if there is no solution, then there is at least one Generalized Contradiction.

\subsection{Application on the case example}

In this paragraph, the Generalized Contradiction model is illustrated on the case example. In order to find a Generalized Contradiction, pairs of sets of evaluation parameters have to be analyzed. The object is not to show the most efficient algorithm to find a Generalized Contradiction in the potentially large number of evaluation parameters set pairs. Three pairs of evaluation parameters set for which a Generalized Contradiction exists are defined.

A first Generalized Contradiction exists between $Y$ " $1=(\mathrm{Y} 5, \mathrm{Y} 6, \mathrm{Y} 7)$ and $\mathrm{Y}$ " $2=(\mathrm{Y} 1, \mathrm{Y} 2)$. The configurations able to provide a satisfying state for each parameter of $Y^{\prime \prime} 1$ are the sixth $X^{\prime}=x^{\prime} 6$ and the eighth $\left(X^{\prime}=x^{\prime} 8\right)$ : lower access area with either external or central engines. For these two options, the height of maximum ramp in corridor when train moves (Y5), the necessity to come back to nominal position to drive (Y6), and the inner height (Y7) are satisfying. Therefore, one can write $\mathrm{S}\left(\mathrm{Y}^{\prime \prime} 1\right)=\left(\mathrm{x}^{\prime} 6, \mathrm{x}^{\prime} 8\right)$. The single configuration able to provide a satisfying value for the two parameters of $\mathrm{Y}^{\prime \prime} 2$ is $\mathrm{x}$ '3: raise whole train with central engines. Therefore $\mathrm{S}\left(\mathrm{Y}^{\prime \prime} 2\right)=\left(\mathrm{x}^{\prime} 3\right)$. For any configuration of $\mathrm{S}(\mathrm{Y}$ "2), the two following parameters are satisfying: the height of module stairs (Y1) and the possibility to make movement when train moves (Y2). As there is no intersection between S(Y"1) and $\mathrm{S}\left(\mathrm{Y}^{\prime \prime 2}\right)$, there is a Generalized Contradiction between these two sets of evaluation parameters. It means that no single configuration in the search solution is able to provide a satisfying value of: the height of module stairs (Y1), the possibility to make movement when train moves (Y2), the height of 
maximum ramp in corridor when train moves (Y5), the necessity to come back to nominal position to drive (Y6), and the inner height (Y7).

The following table shows how the initial technical data can be reorganized to graphically find this Generalized Contradiction.

\begin{tabular}{|l|c|c|c|c|c|c|c|c|c|c|c|}
\hline & $\mathrm{Y} 5$ & $\mathrm{Y} 6$ & $\mathrm{Y} 7$ & $\mathrm{Y} 1$ & $\mathrm{Y} 2$ & $\mathrm{Y} 3$ & $\mathrm{Y} 4$ & $\mathrm{Y} 8$ & $\mathrm{Y} 9$ & $\mathrm{Y} 10$ \\
\hline \#6 & 1 & 1 & 1 & 0 & 0 & 0 & 0 & 1 & 1 & 1 \\
\hline \#8 & 1 & 1 & 1 & 0 & 0 & 0 & 0 & 1 & 1 & 1 \\
\hline \#3 & 0 & 0 & 0 & 1 & 1 & 0 & 0 & 0 & 0 & 0 \\
\hline \#2 & 1 & 0 & 0 & 0 & 0 & 1 & 1 & 0 & 0 & 0 \\
\hline \#5 & 0 & 1 & 1 & 0 & 0 & 0 & 0 & 1 & 1 & 1 \\
\hline$\# 7$ & 0 & 1 & 1 & 0 & 0 & 0 & 0 & 1 & 1 & 1 \\
\hline$\# 1$ & 0 & 0 & 0 & 0 & 1 & 0 & 0 & 0 & 0 & 0 \\
\hline$\# 4$ & 0 & 0 & 0 & 1 & 0 & 0 & 0 & 0 & 0 & 0 \\
\hline
\end{tabular}

Table 7. Representation of a generalized contradiction

Using the OTSM System of Contradictions graphical scheme, this Generalized Contradiction can be illustrated like:

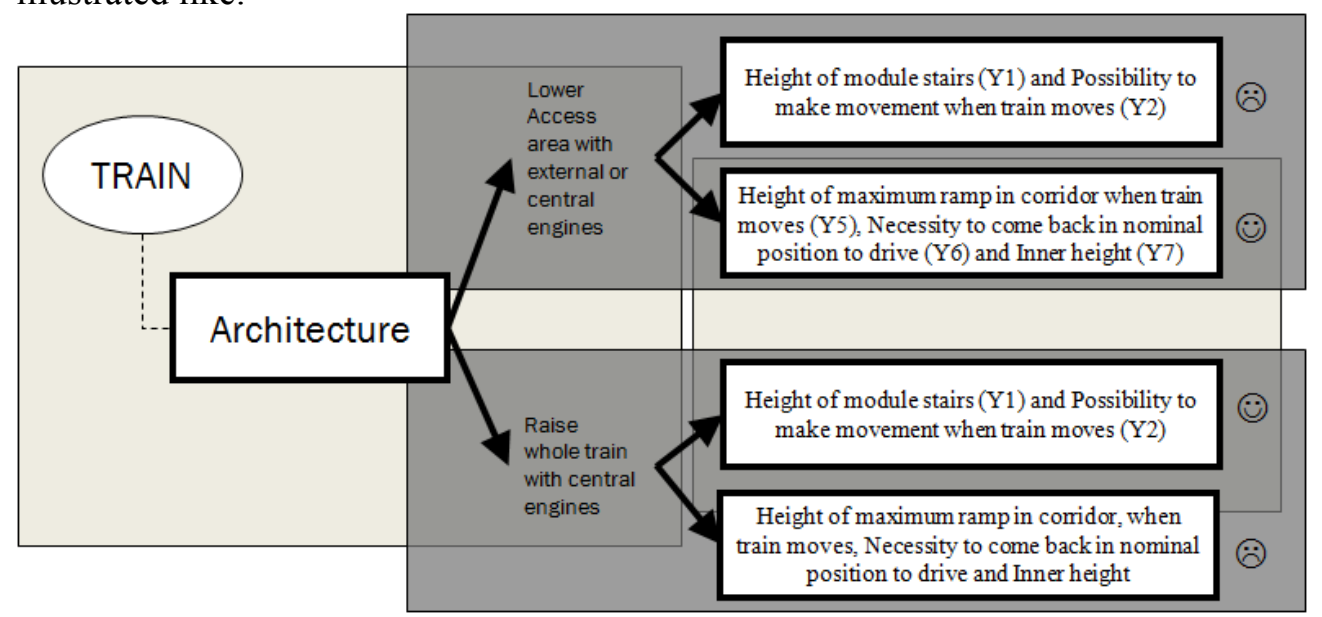

Figure 4. Graphical representation of a generalized contradiction

These two other tables show two other Generalized Contradictions:

- Table 8a: a GC exists between $\mathrm{Y}^{\prime \prime} 1=(\mathrm{Y} 3, \mathrm{Y} 4, \mathrm{Y} 5)$ and $\mathrm{Y}$ ' $2=(\mathrm{Y} 8, \mathrm{Y} 9, \mathrm{Y} 10)$. No single configuration is able to provide a satisfying value for these two sets;

- Table 8b: a GC exists between $\mathrm{Y}^{\prime \prime} 1=(\mathrm{Y} 1, \mathrm{Y} 2)$ and $\mathrm{Y}^{\prime}{ }^{\prime} 2=(\mathrm{Y} 6, \mathrm{Y} 7, \mathrm{Y} 8, \mathrm{Y} 9, \mathrm{Y} 10)$.

\begin{tabular}{|l|l|l|l|l|l|l|l|l|l|l|}
\hline Y3 & Y4 & Y5 & Y8 & Y9 & Y10 & Y1 & Y2 & Y6 & Y7 \\
\hline
\end{tabular}

\begin{tabular}{|c|c|c|c|c|c|c|c|c|c|c|}
\hline$\frac{x^{\prime} 2}{2}$ & 1 & 1 & 1 & 0 & 0 & 0 & 0 & 0 & 0 & 0 \\
\hline$x^{\prime} 5$ & 0 & 0 & 0 & 1 & 1 & 1 & 0 & 0 & 1 & 1 \\
\hline \begin{tabular}{|l}
$x^{\prime} 6$ \\
\end{tabular} & 0 & 0 & 1 & 1 & 1 & 1 & 0 & 0 & 1 & 1 \\
\hline$x^{\prime} 7$ & 0 & 0 & 0 & 1 & 1 & 1 & 0 & 0 & 1 & 1 \\
\hline$x^{\prime} 8$ & 0 & 0 & 1 & 1 & 1 & 1 & 0 & 0 & 1 & 1 \\
\hline $\mathrm{X}^{\prime} 1$ & 0 & 0 & 0 & 0 & 0 & 0 & 0 & 1 & 0 & 0 \\
\hline$x^{\prime} 3$ & 0 & 0 & 0 & 0 & 0 & 0 & 1 & 1 & 0 & 0 \\
\hline \begin{tabular}{|l|}
$x^{\prime} 4$ \\
\end{tabular} & 0 & 0 & 0 & 0 & 0 & 0 & 1 & 0 & 0 & 0 \\
\hline
\end{tabular}

\begin{tabular}{|l|l|l|l|l|l|l|l|l|l|}
\hline Y1 & $Y 2$ & $Y 6$ & $Y 7$ & $Y 8$ & $Y 9$ & $Y 10$ & $Y 3$ & $Y 4$ & $Y 5$ \\
\hline
\end{tabular}

\begin{tabular}{|c|c|c|c|c|c|c|c|c|c|c|}
\hline x'3 & 1 & 1 & $\overline{0}$ & 0 & 0 & $\overline{0}$ & 0 & $\overline{0}$ & 0 & 0 \\
\hline \begin{tabular}{|l}
$x^{\prime} 5$ \\
\end{tabular} & 0 & 0 & 1 & 1 & 1 & 1 & 1 & 0 & 0 & 0 \\
\hline$x^{\prime} 6$ & 0 & 0 & 1 & 1 & 1 & 1 & 1 & 0 & 0 & 1 \\
\hline $\mathrm{x}^{\prime} 7$ & 0 & 0 & 1 & 1 & 1 & 1 & 1 & 0 & 0 & 0 \\
\hline x'8 & 0 & 0 & 1 & 1 & 1 & 1 & 1 & 0 & 0 & 1 \\
\hline \begin{tabular}{|l|}
$x^{\prime} 1$ \\
\end{tabular} & 0 & 1 & 0 & 0 & 0 & 0 & 0 & 0 & 0 & 0 \\
\hline $\mathrm{x}^{\prime} 2$ & 0 & 0 & 0 & 0 & 0 & 0 & 0 & 1 & 1 & 1 \\
\hline $\mathrm{x}^{\prime} 4$ & 1 & 0 & 0 & 0 & 0 & 0 & 0 & 0 & 0 & 0 \\
\hline
\end{tabular}

Table 8. Different representations of a generalized contradiction

This case example also shows that for a single problem more than one Generalized Contradiction can be found. To conclude this case example, one can say that although OTSM-TRIZ System of Contradiction failed in stating the contradiction to be solved, it is possible to apply a dialectic model (Generalized Contradiction) to describe an unsolvable problem. 


\section{Discussion and prospects}

The proposed model succeeded in bringing a model bridging optimization methods and inventive problem solving tools by satisfying the equivalence requirement between the lack of solution (in terms of optimization) and the existence of contradiction (in term of property that can be found in the problem description). Moreover the Generalized Contradiction model is a model from the same level of formalization as the System of Contradiction of OTSM-TRIZ, since contradiction between evaluation parameters can be expressed, and this contradiction can also be expressed as two different states of the action parameter combination. The article revealed the limitations of OTMS-TRIZ system of contradictions as the model cannot fit all solutionless problems.

The proposed model application can be extended to any source of information that can be transcribed in the shape of a chart, but such a chart is a prerequisite to its application. Thus it can very well comply with Constrain Satisfaction Problems (CSP). A future research subject will be to build new problem solving techniques for CSP in order to automate the elicitation of Generalized Contradiction when no solution can be found.

Another research trend will be to analyze the modes of problem model transformation to solve the contradiction, and define the most efficient dialectical model in accordance with the efficiency of the solution found by solving a contradiction. But to reach this goal the applicability of solving rules from OTSM-TRIZ to Generalized Contradiction has to be tested and validated.

The proposed model deals with contradiction based on combinations of parameters that are not necessarily completely understood. These combinations can be determined by computers, but the rules to change the OTSM-TRIZ model are mainly have been created to change the human perspective. In this article a model named "Generalized Contradiction" has been built on a property which is equivalent to the absence of a solution. When comparing this article and (Eltzer and De Guio 2007) the properties defining the Generalized Contradiction are slightly different, but both satisfy the equivalence requirement. To choose which property is the most suitable (between the two presented or maybe others) the application of the models for problem resolution has to be performed.

\section{References}

[1] F.S. Hillier, G.J. Lieberman, Introduction to Operations Research, McGraw-Hill (2005).

[2] V. Kumar, Algorithms for constraint-satisfaction problems: a survey, AI Magazine 1 (1) (1992) 32-44.

[3] Ö. Akin, Variants in Design Cognition, Design Knowing and Learning: Cognition in Design Education, W. N. C. Eastman, M. McCracken. Atlanta, GA, USA, Elsevier (2001) 105-124.

[4] O.Z. Maimo, R. Horowitz, Sufficient Conditions for Inventive Solutions, IEEE Transactions on Systems, Man and Cybernetics - Part C: Applications and reviews 29 (3) (1999) 349-361.

[5] D.L. Dekker, Engineering Design Processes, Problem Solving and Creativity, ASEE/IEEE Frontiers in Education '95, Atlanta, GA (1995).

[6] T. Eltzer, R. De Guio, Constraint based modelling as a mean to link dialectical thinking and corporate data. Application to the Design of Experiments, 2nd IFIP Working Conference on Computer Aided Innovation, Brighton, USA, Springer (2007).

[7] J. Rowan, Ordinary Ecstasy: The Dialectics of Humanistic Psychology, Routledge (2001).

[8] G.S. Altshuller, Creativity as an Exact Science, New York, Gordon and Breach (1988).

[9] V. Goepp, F. Kiefer, F. Geiskopf, Design of information system architectures using a keyproblem framework, Computers in Industry 57 (2) (2006) 189-200.

[10] F. Geiskopf, Formalisation et Exploitation des contraintes Produit/Process pour la conception de systèmes de production; application à l'usinage Grande Vitesse. Strasbourg, Université Louis Pasteur (2004).

[11] N. Khomenko, R. De Guio, L. Lelait; I. Kaikov, A framework for OTSM-TRIZ-based computer support to be used in complex problem management, International Journal of Computer Applications in Technology 30 (1/2) (2007) 88-104.

[12] L. Spencer, A. Krauze, Hegel for beginners, Trumpington, Icon (1996).

[13] V.I. Lenin, Conspectus of Hegel's The Science of Logic, Moscow (1958). 
[14] S. Scolnicov, Plato's Parmenides, LA, University of California Press (2003).

[15] F. Engels, Dialectics of Nature, M.I.A. Library, Marx \& Engels (1925).

[16] M. Tsetung, On Contradiction, Selected Works, F. L. Press, Peking (1967) 311-347.

[17] G.S. Altshuller, R. B. Shapiro, Psychology of Inventive Creativity, Issues of Psychology 6 (1956) 37-49.

[18] S.D. Savransky, Engineering of Creativity: Introduction to TRIZ Methodology of Inventive Problem Solving, Boca Raton, Florida, CRC Press LLC (2000).

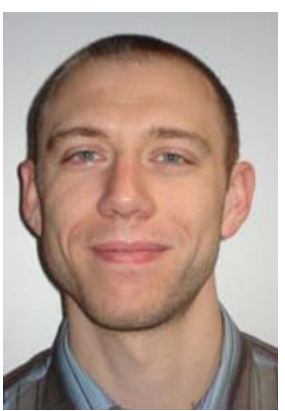

Sébastien Dubois is Research Engineer in INSA Strasbourg graduate school of science and technology. He is supporting research activities in the field of innovative and inentive methods for technical problems solving. He teaches at the master level the inventive problem solving methods. Engineer of the Superior National University in Arts and Industry of Strasbourg in 2000 and Doctor of the University of Strasbourg in Engineering Sciences in 2004, he was researcher in the INSA Strasbourg graduate school of science and technology since 2004 until 2006. During this period, he has developed research on inventive theory for problem solving and he also built an e-learning module on the Theory for Inventive Problem Solving (TRIZ).

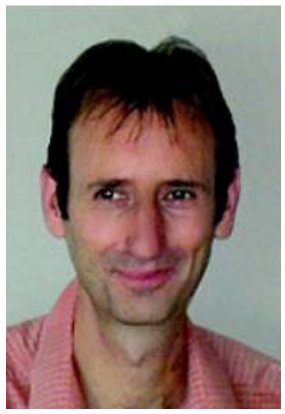

Roland De Guio is full professor in Industrial Engineering at I.N.S.A of Strasbourg, France. He is member of the Production Research Laboratory of Strasbourg. His research addresses the applications of data analysis, artificial intelligence and theory of inventive problem solving in the area of management and design of production systems. Most of his research are undertaken in partnership with companies.

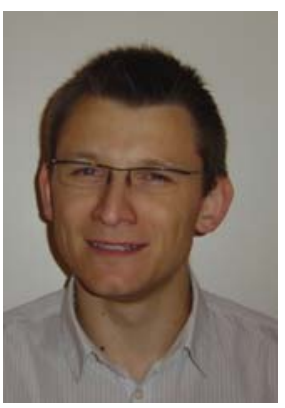

Thomas Eltzer works in the field of inventive problem solving, and mainly in the area of complex problem modelisation. As a TRIZ specialist, he aims at applying the principles of TRIZ in a broader sense and to contribute to the formalization of this problem solving approach. He published the result of his research in numerous conferences and journals. He has tought and applied inventive problem solving methodologies in both academic and industrial conditions. He works now as an Innovation Project Manager in Active Innovation Management Sarl, a french consulting company. A part of his time is dedicated to the improvement of the innovation techniques, and especially the development of computer based tools, in strong cooperation with research. 